\title{
Mismatch between physicians and family members views on communications about patients with chronic incurable diseases receiving care in critical and intensive care settings in Georgia: a quantitative observational survey
}

Nana Chikhladze ${ }^{1,3^{*}}$ D. Elene Janberidze ${ }^{2,3}$, Mariam Velijanashvili, ${ }^{1,3}$, Nikoloz Chkhartishvili ${ }^{3,4}$, Memed Jintcharadze $^{3}$, Julia Verne $e^{5}$ and Dimitri Kordzaia ${ }^{1,2,3}$

\begin{abstract}
Background: Physicians working in critical and intensive care settings encounter death of chronic incurable patients on a daily basis; however they have scant skills on how to communicate with the patients and their family members. The aim of the present survey is to examine communication of critical and intensive care physicians with patients' family members receiving treatment due to chronic incurable diseases/conditions and to compare the views of families with physicians working in critical and intensive care settings.

Methods: The survey was conducted in four cities of Georgia (Tbilisi, Kutaisi, Batumi and Telavi) in 2014. Physicians working in critical and intensive care settings and family members were asked to fill in separate questionnaires, covering various aspects of communication including patients' prognosis, ways of death occurrence, treatment plans and religion. Participants ranked their responses on a scale ranging from " 0 " to " 10 ", where " 0 " represented "never" and " 10 "-"always". After data collection, responses were recoded into three categories: $0-3=$ never/rarely, $4-7=$ somewhat and 8-10 = often/always. Differences were tested using Pearson's chi-square or Fisher's exact test as appropriate. $P$ value of $<0.05$ was considered as significant.
\end{abstract}

Results: Sixty-five physicians and 59 patients' family members participated in this cross-sectional study. Majority of their responses was statistically significantly different. Only one quarter (23.7 \%) of family members of patients receiving medical aid in critical and intensive care settings were satisfied with the communication level. In contrast, $78.5 \%$ of physicians considered their communication with families as positive $(p<0.0001)$.

\footnotetext{
* Correspondence: nanuka.chikhladze@yahoo.com

${ }^{1}$ Iv. Javakhishvili Tbilisi State University (TSU), Tbilisi, Georgia

${ }^{3}$ Georgian National Association for Palliative Care, Tbilisi, Georgia

Full list of author information is available at the end of the article
} 
(Continued from previous page)

Conclusions: The survey revealed the mismatch between the views on communication of critical and intensive care settings physicians and family members of the patients with chronic incurable diseases receiving care in critical and intensive care settings. In order to provide the best care for chronic incurable patients and their family members, physicians working in critical and intensive care settings must have relevant clinical knowledge and ability to provide effective communication. Present results reflect important potential targets for educational interventions including critical and intensive care physicians training through online modules.

Keywords: Observational survey, Critical/Intensive care physicians, Patients' family members, Palliative care, Mismatch in views on communications

\section{Background}

Critical and Intensive Care (CIC) is the setting for the death of many cancer patients around the world, however the proportion of patients dying in acute care hospitals and in CIC settings vary [1]. Previously, concerns have been raised about the costs associated with admission to $\mathrm{CIC}$ for terminally ill cancer patients; at the same time, the issue related to the withholding and withdrawal of life prolonging treatment has always been challenging [2]. Therefore death in hospital is often contrary to patients' wishes, many of whom would prefer to die at home [3-5]. Many patients with serious and life-threatening illness are admitted to CIC settings because the symptoms cannot be controlled at home or in the community setting $[6,7]$, however question about 'futility' of some types of care provided to terminally ill patients in CIC settings is being increasingly debated [8]. Although, many patients die in CIC settings, the purpose of being admitted is to attempt to prolong life. Expectations and hopes of the patients' relatives are often raised. However, the CIC physicians may have limited training and resources to manage and respond well to patients who have palliative care needs, nor to fully respect these patients' preferences and expectations $[9,10]$. Despite encountering death on a daily basis physicians in CIC settings are not always trained in delivering bad news [11]. In addition, in Georgia, physicians do not feel comfortable to break bad news with patients or their relatives about poor prognosis or the futility of treatment [12].

In Georgia, after restoration of independence in April 9, 1991, there has not only been an improvement in the quality of medical care, but also significant change in medical values accompanying a return to Georgian traditions and culture. For example, in soviet times, when atheism dominated, death was considered to be something which medical technology should attempt to prevent at all costs, but not as the normal consequence of life accompanied by spiritual preparation for the patient and family. Restoration of independence returned Georgia to traditional cultural values, which included a strong influence of Orthodox Christianity. In the first years of independence, the "Law on Healthcare", "Law on Patients' Right" and "Law on Medical Activities" were approved by the Parliament of Georgia. In addition, Bioethical National Council has been created. Sharing of diagnosis with the patient and their family members became mandatory, therefore new regulations made doctors to re-consider death as natural part of end-of-life. This requires special preparation from medico-biological, as well as, spiritual points of view. Since 2007 palliative care has been recognised in Georgia as a sub-speciality for four specialties: "Internal Medicine", "Surgery", "Oncology" and "Reanimatology/Intensive Therapy". Later, in 2014 the list of such specialties was increased up to 11 [13]. Implementation of educational/training courses in palliative care aimed to develop more holistic approach to the care of dying patients considering their physical, psychological social and spiritual needs. However, while the concepts of and training in palliative care are being implemented in Georgian medical field, some branches including $\mathrm{CIC}$, still need more time to fully integrate these principles in their professional practice.

It is confirmed, that realization of patient's imminent death leads to potential changes in management which includes clarifying of treatment goals, improving communication with families, spending more time with patients and ordering fewer laboratory tests [14]. However, a previous study conducted in 2009-2010 in two Georgian cities (Tbilisi and Batumi) showed that number of Georgian physicians, especially in CIC settings, due to their scant knowledge of palliative care, follow their traditional goals to "cure" the patient or "postpone death" [15]. The study showed that it may lead to neglecting or missing the opportunity to meet the more holistic needs of patients and their families. 29 from 2000 (14.5\%) of advanced cancer patients spent their last days and hours in CIC settings. Family members of more than half of these patients had different complains regarding the care provided to the patients and were dissatisfied with communication with medical staff.

Patients' families play a significant role in demanding the transfer of advanced cancer patient to CIC setting. These demands are partially made because they are not aware that their relative is in a terminal condition and 
also because of continued hope of "delaying death" [15]. As a high proportion of the cancer patients who die in CIC have altered state of consciousness, families play an essential role in making decisions on their behalf [16]. This means that good communication between physicians and family members of advanced cancer patients in CIC settings is critical to ensure the best possible holistic care [14].

Studies conducted during the last decade in US and UK showed the importance of improvement and/or development of palliative care competencies in CIC settings $[17,18]$. This implies the standards providing symptom control, pain relief and achievement of maximal physical comfort, as well as, consistency with humanistic goals, ethical and psychological support to patients and their families At the same time, implementation of palliative care approaches in CIC settings is related with difficulties of switching abruptly from curative approach to preparation for dying which itself may vary from several hours to several weeks [19]. To improve communication with family members is one of the important issues in this aspect [14].

The aim of this survey is to compare the views of family members of the patients receiving treatment due to chronic incurable diseases/conditions in CIC settings and CIC physicians-on various aspects of their essential communications regarding the patients (prognosis, ways of death occurrence, further treatment plan discussion, faith, spiritual attitudes and religiousness).

\section{Methods}

\section{Study design, settings and participants}

Cross-sectional study was conducted from February 2014 through July 2014. Convenience sampling approach was used and consecutive numbers of participants were enrolled over the study period.

The eligibility criteria: The physicians working in CIC settings in four cities of Georgia (Tbilisi, Kutaisi, Batumi and Telavi) with at least 4 years of work experience but with no specific training in palliative care.

Family members of adult patients (age $\geq 18$ years) receiving medical care in the same hospitals of recruited physicians were invited to participate in the survey. $\mathrm{Pa}$ tients' family members were chosen for the study as the contact with terminal incurable patients in CIC settings frequently is difficult or impossible due to patients have altered state of consciousness. The study exclusion criteria were patients' family members with limited or no knowledge of Georgian language.

Physicians and patients' family members were recruited independently, and physicians were not required to be the primary care provider of the recruited patient. Patients' personal information (e.g. age, sex, diagnosis and date of death) was provided by patients' family members based on standardized discharge/death certificate issued by the hospital (the data is available in Table 1).

\section{Instrument}

The two separate questionnaires with parallel questions for physicians and family members were designed by team of experts working in CIC settings, palliative care, psychology, and ethics. The questionnaire was covering various aspects of communication including, but not limiting to, patients prognosis, expected time of death, treatment plans and religion. Questionnaires were reviewed by field experts for content validity and was piloted in six volunteers not taking part in survey (three CIC physicians and three family members of patients with cancer died in CIC setting) to ensure that all participants understand the questions correctly. The list of questions used in the study is shown in Table 2. The questionnaires were self-administered in presence of one of the researchers who explained the instrument to participants. Participants were asked to rank their responses on a scale ranging from 0 to 10 where " 0 " represented "never" and "10"-"always". But for questions Q1.9Q2.9-"0" represented "very difficult" and "10"-"absolutely not difficult" and for questions Q1.10-Q2.10-"0" represented "fully Negative" and "10"-"fully positive".The data presented in Table 2 was disintegrated into separate figures in order to show the results of interviewing for each question in more simplicated way (see Additional file 1: Figure S1 - S10).

Participants also had the option "do not know" for every question. Each participant had only one session for filling questionnaires.

\section{Statistical analysis}

After data collection, responses to the questionnaires were recoded into three categories: $0-3=$ never/rarely, $4-7=$ somewhat and $8-10=$ often/always. Answers on "do not know" were classified separately.

Standard, descriptive statistics were conducted to access variable distributions. Comparisons between physician and patients' family members responses were tested in bivariate analysis for each individual questionnaire item. Differences were tested both for entire item and for each individual response category using Pearson's chi-square or Fisher's exact test as appropriate. Fisher's exact test was used if the number of responses in any category to be tested was $\leq 5$, otherwise preference was given to Pearson's chi-square test [20]. Two-sided significance tests were used and $p$ value of $<0.05$ was considered as significant.

\section{Results}

A total of 68 physicians working in CIC settings were approached, among them 65 (response rate $95.6 \%$ ) 
Table 1 Characteristics of the patients whose family members participated in the study ${ }^{a}$ denotes the number of died patients

\begin{tabular}{|c|c|c|c|c|c|c|c|c|c|}
\hline \multirow{3}{*}{$\begin{array}{l}\text { Age, Gender } \\
\text { Diagnoses }^{a}\end{array}$} & \multicolumn{2}{|l|}{$25-40$} & \multicolumn{2}{|l|}{$41-60$} & \multicolumn{2}{|l|}{$60-74$} & \multicolumn{2}{|l|}{$75-80$} & \multirow[t]{3}{*}{ Sum } \\
\hline & Woman & Man & Woman & Man & Woman & Man & Woman & Man & \\
\hline & 2 & 3 & 6 & 7 & 11 & 9 & 9 & 12 & \\
\hline Breast Cancer, multiple metastases, multiorgan failure & 1 & - & $3(1)^{a}$ & - & $4(1)$ & - & - & - & $8(2)$ \\
\hline Pancreatic Head Cancer, Mechanical Jundice, Ascites. & - & - & 1 & 1 & - & $1(1)$ & $1(1)$ & $1(1)$ & $5(3)$ \\
\hline Gallblader Duct Cancer, Cholangiostomic Obstruction & - & - & - & - & - & - & - & $1(1)$ & $1(1)$ \\
\hline Liver Cancer, Hepatic Failure & - & - & - & 1 & - & $2(2)$ & - & - & $3(2)$ \\
\hline Lung Cancer, Multiple Bone Metastases & - & 1 & 1 & - & - & 1 & - & $1(1)$ & $4(1)$ \\
\hline Kidney Cancer, Multiple Bone Metastases & - & - & - & 1 & - & 1 & - & - & 2 \\
\hline Mediastinal Hodgkin's Lymphoma,Multiorgan Failure & - & - & - & - & 1 & - & 1 & - & 2 \\
\hline Retroperitoneal Lymphoma, Multiorgan Failure & - & - & - & 1 & - & - & $1(1)$ & - & $2(1)$ \\
\hline Diabetes, Osteoporoses, Femoral Head Fracture, Kidney Failure & - & - & 1 & - & - & - & 2 & - & 3 \\
\hline Prostate Cancer, Ascites, Multiorganic Failure. & - & - & - & 2 & - & $2(1)$ & - & - & $4(1)$ \\
\hline Acute Stroke, Cerebral Coma & - & - & - & - & 1 & - & - & $2(1)$ & $3(1)$ \\
\hline Post Stroke Condition, Partial Intestinal Obstruction & 1 & 1 & - & - & 1 & $2(1)$ & 1 & $1(1)$ & $7(2)$ \\
\hline Alzheimer's Disease & - & - & - & - & 1 & - & - & 1 & 2 \\
\hline Heart Failure, Dementia & - & - & - & - & - & - & 1 & 1 & 2 \\
\hline Uterine Cancer, Multiple Metastases, Hydrothorax, Ascites & - & - & - & - & 3 & - & 1 & - & 4 \\
\hline Esophageal Cancer, Gastrostoma, Dementia & - & - & - & - & - & - & - & $1(1)$ & $1(1)$ \\
\hline Large Intestinal Cancer, Terminal Ileostoma, & - & - & - & - & - & - & 1 & $2(1)$ & $3(1)$ \\
\hline Liver Ciroses, Esophageal Varicose Bleeding, Multiorganic Failure & - & 1 & - & $1(1)$ & - & - & - & $1(1)$ & $3(2)$ \\
\hline Sum & 5 & & $13(2)$ & & $20(6)$ & & $21(9)$ & & $59(17)$ \\
\hline
\end{tabular}

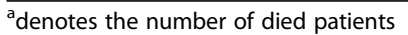

agreed and took part in the survey.. The age range of the physicians was 31-74, female-25, male-40. Professional experience of the physicians varied from 4 to 48 years.

Of 70 family members of patients with chronic incurable disease receiving care in CIC settings were approached and 59 (response rate $84.3 \%$ ) participated in the survey. Results of quantitative analysis for the responses on both questionnaires are presented in Table 2.

Comparison of physicians' and patients' family members" responses to paired questions showed substantial differences. Except for question Q1.2/Q2.2 on patient's life expectancy, differences in responses to all other items were statistically significant. For example, the vast majority of physicians $(86.2 \%)$ reported that they often/always discussed the possible deterioration of a patient's condition whereas the less than half of patients' family members $(47.5 \%)$ reported often/always being given this information $(p<0.0001)$.

Seventy point eight percent of physicians reported that they have never/rarely discussed with the patient how death may occur (Q1.3), but $40 \%$ reported that they often/always have this discussion with patients' family members (Q1.4). However, only $15.3 \%$ of patients' family members confirmed such discussions (Q2.4) $(p=0.002)$.

The majority of physicians $(84.6 \%)$ reported to have discussions about future treatment plans, (e.g. use of cardiopulmonary rresuscitation or breathing support devices) as "often/always", but the same assessment was reported from patients' family members only in $57.4 \%$.

Half (50.8\%) of patients' family members reported that physician never/rarely talked about life related topics associated and important to the patient, as compared to $10.8 \%$ reported by physicians Q1.6/Q2.6 ( $p<0.0001)$. As for the respect to patients' spiritual attitudes and religiousness, $64.6 \%$ of CIC physicians said that they often/always had demonstrated such respect, while only $6.8 \%$ patients' family members felt that the physicians did so (Q1.8/Q2.8) $(p<0.0001)$.

Only one quarter $(24.8 \%)$ of patients' family members receiving medical aid in CIC settings were satisfied with the communication level (Q2.10). The reason for their dissatisfaction was sense of inadequate appreciation of their needs and requirments. In contrast, $78.5 \%$ of CIC physicians considered their communication with patients' family members as positive (Q1.10) $(<0.0001)$. 
Table 2 Descriptive statistics of the responses from the physicians working in Critical and Intensive Care (CIC) settings and patients' family members

\begin{tabular}{|c|c|c|c|c|c|c|c|c|c|}
\hline \multirow{2}{*}{$\begin{array}{l}\text { Responses } \\
\text { Physicians/patients' family members }\end{array}$} & \multicolumn{2}{|c|}{ Never/Rarely } & \multicolumn{2}{|c|}{ Somewhat } & \multicolumn{2}{|c|}{ Often/Always } & \multicolumn{2}{|c|}{ Don't know } & \multirow[t]{2}{*}{ Overall $P$ value } \\
\hline & $\overline{n(\%)}$ & $P$ value & $n(\%)$ & $P$ value & $n(\%)$ & $P$ value & $n(\%)$ & $P$ value & \\
\hline $\begin{array}{l}\text { Physicians } \\
\text { Q1.1. Do you talk with the patient and/or family } \\
\text { members about the details, related to the } \\
\text { possible deterioration of the health condition of } \\
\text { the patient? }\end{array}$ & $1(1.5)$ & 0.003 & $8(12.3)$ & 0.004 & $56(86.2)$ & $<0.0001$ & 0 & 0.48 & $<0.0001$ \\
\hline $\begin{array}{l}\text { Patients' family members } \\
\text { Q2.1 Did the doctor talk with you, as the family } \\
\text { member, about the details, related to the possible } \\
\text { deterioration of the health condition of the patient? }\end{array}$ & $10(16.9)$ & & $20(33.9)$ & & $28(47.5)$ & & $1(1.7)$ & & \\
\hline $\begin{array}{l}\text { Physicians } \\
\text { Q1.2 Do you inform the patient and/or family } \\
\text { members, about the exact time interval the } \\
\text { patient might live? }\end{array}$ & $12(18.5)$ & 0.17 & $24(36.9)$ & 0.88 & $26(40.0)$ & 0.61 & $3(4.6)$ & 0.25 & 0.26 \\
\hline $\begin{array}{l}\text { Patients' family members } \\
\text { Q2.2 Did the doctor inform you, as the patient's } \\
\text { family member, about the exact time interval } \\
\text { the patient might live? }\end{array}$ & $17(28.8)$ & & $21(35.6)$ & & $21(35.6)$ & & 0 & & \\
\hline $\begin{array}{l}\text { Physicians } \\
\text { Q1.3 Do you discuss with the patient how his/her } \\
\text { death may occur? }\end{array}$ & $46(70.8)$ & - & $17(26.2)$ & - & $2(3.1)$ & - & 0 & - & - \\
\hline Patients' family members & - & - & - & - & - & - & - & & \\
\hline $\begin{array}{l}\text { Physicians } \\
\text { Q1.4Do you discuss with the family members } \\
\text { about how the patient's death may occur? }\end{array}$ & $10(15.4)$ & $<0.0001$ & $29(44.6)$ & 0.66 & $26(40.0)$ & 0.002 & 0 & - & 0.0004 \\
\hline $\begin{array}{l}\text { Patients' family members Q2.4 Did the doctor } \\
\text { discuss with you about how the patient's death } \\
\text { may occur? }\end{array}$ & $26(4.1)$ & & $24(40.7)$ & & $9(15.3)$ & & 0 & & \\
\hline $\begin{array}{l}\text { Physicians } \\
\text { Q1.5 Did you discuss the further treatment } \\
\text { strategy (e.g. CPR, use of breathing support } \\
\text { devices,) with the patient and/or family members? }\end{array}$ & $3(4.6)$ & 0.07 & $7(10.8)$ & 0.02 & $55(84.6)$ & 0.001 & $000 \circ 0$ & - & 0.004 \\
\hline $\begin{array}{l}\text { Patients' family members Q2.5 Did the doctor } \\
\text { discuss with you the further treatment strategy } \\
\text { e.g. CPR, use of breathing support devices? }\end{array}$ & $9(15.3)$ & & $16(27.1)$ & & $34(57.6)$ & & 0 & & \\
\hline $\begin{array}{l}\text { Physicians } \\
\text { Q1.6 Do you talk to the patient and/or family } \\
\text { member about life-related topics associated and } \\
\text { important to the patient? }\end{array}$ & $7(10.8)$ & $<0.0001$ & $33(50.8)$ & 0.002 & $23(35.4)$ & 0.10 & $2(3.1)$ & 0.81 & $<0.0001$ \\
\hline $\begin{array}{l}\text { Patients' family members Q2.6 Did the doctor } \\
\text { talk with you about life-related topics associated }\end{array}$ & $30(50.8)$ & & $14(23.7)$ & & $13(22.0)$ & & $2(3.4)$ & & \\
\hline
\end{tabular}

Patients' family members

$10(16.9)$

$20(33.9)$

deterioration

Q1.2 Do you inform the patient and/or family

patient might live?

Q2.2 Did the doctor inform you, as the patient's

family member, about the exact time interval

Physicians

Patients' family members

Physicians

Q1.5 Did you discuss the further treatment

devices,) with the patient and/or family members?

Patients' family members Q2.5 Did the doctor

with you the further treatment strategy

Physicians

Q1.6 Do you talk to the patient and/or family important to the

and important to the patient? 
Table 2 Descriptive statistics of the responses from the physicians working in Critical and Intensive Care (CIC) settings and patients' family members (Continued)

\begin{tabular}{|c|c|c|c|c|c|c|c|c|c|}
\hline $\begin{array}{l}\text { Physicians } \\
\text { Q1.7 Do you talk with the patient about his/her } \\
\text { faith (religion)? }\end{array}$ & $23(40.0)$ & $<0.0001$ & $23(40.0)$ & 0.02 & $11(16.9)$ & 0.05 & 0 & - & $<0.0001$ \\
\hline $\begin{array}{l}\text { Patients' family members Q2.7 Did the doctor talk } \\
\text { with about the Patient's faith (religion)? }\end{array}$ & $46(78.0)$ & & $10(16.9)$ & & $3(5.1)$ & & 0 & & \\
\hline $\begin{array}{l}\text { Physicians } \\
\text { Q1.8 Do you respect the spiritual attitudes and } \\
\text { religiousness of the patient? }\end{array}$ & $0(0.0)$ & $<0.0001$ & $23(35.4)$ & 0.01 & $42(64.6)$ & $<0.0001$ & $0(0.0)$ & $<0.0001$ & $<0.0001$ \\
\hline \multirow{2}{*}{$\begin{array}{l}\text { Patients' family members Q2.8 Did the doctor } \\
\text { show respect towards the patient's spiritual } \\
\text { attitudes and religiousness? }\end{array}$} & $29(49.2)$ & & $9(15.3)$ & & $4(6.8)$ & & $17(28.8)$ & & \\
\hline & \multicolumn{2}{|l|}{ Very difficult } & \multicolumn{2}{|l|}{ Somewhat } & \multicolumn{2}{|l|}{ Not at all } & \multicolumn{2}{|l|}{ Don't know } & \\
\hline $\begin{array}{l}\text { Physicians } \\
\text { Q1.9 Do you find it difficult to talk with the } \\
\text { patient and/or his family about the patient's } \\
\text { death? }\end{array}$ & $11(16.9)$ & 0.05 & $39(60.0)$ & 0.40 & $15(23.1)$ & 0.02 & 0 & - & 0.0219 \\
\hline \multirow{2}{*}{$\begin{array}{l}\text { Patients' family members Q2.9 Was it difficult for } \\
\text { the doctor to talk with you about the patient's } \\
\text { death? }\end{array}$} & $3(5.1)$ & & $31(52.5)$ & & $25(42.4)$ & & 0 & & \\
\hline & \multicolumn{2}{|l|}{ Negative } & \multicolumn{2}{|l|}{ Somewhat } & \multicolumn{2}{|l|}{ Positive } & \multicolumn{2}{|l|}{ Don't know } & \\
\hline $\begin{array}{l}\text { Physicians } \\
\text { Q1.10 How would you appraise your communication } \\
\text { with the patient in general? }\end{array}$ & $1(15.0)$ & 0.001 & $13(20.0)$ & $<0.0001$ & $51(78.5)$ & $<0.0001$ & 0 & - & $<0.0001$ \\
\hline $\begin{array}{l}\text { Patients' family members Q2.10 How would you } \\
\text { appraise doctors' communication with you in } \\
\text { general? }\end{array}$ & $12(20.3)$ & & $33(55.9)$ & & $14(23.7)$ & & 0 & & \\
\hline
\end{tabular}




\section{Discussion}

This is the first survey conducted in CIC settings in Georgia, an example of the country where medical care is developing according to western standards [21], however communication skills still lag [12]. We examined the communication between physicians and family member of the patients dying from chronic incurable diseases in CIC settings. We wanted to demonstrate the possible mismatch between what physicians say and what families say about their communication. For almost every question the answers provided by physicians and patients' family members significantly differ from each other. The exception is the assessment of communication regarding the prognosis, in particular, the length of time the patient was expected to live. For this question the physicians and family members gave a similar evaluation of the communication process: $55,4 \%$ of physicians and $64,4 \%$ of patients' family members recognize that this question was addressed "never/rarely" or "somewhat". It may reflect that the real difficulty lies in establishing precise prognosis, thus physicians may be cautious about communicating how long the patient can live. The significant contrast in responses to paired questions highlights the problems in communication between $\mathrm{CIC}$ physicians and patients' family members in this aspect. Despite the fact, that $40,0 \%$ of CIC physicians think, that they"often" discuss with patients' family members how and in what conditions the patient could die, these assumptions are confirmed only by $15,3 \%$ of patients' family members $(p<0,002)$. The similar differences in responses are revealed for questions regarding the communication about further treatment plans: $84,6 \%$ of CIC physicians think that they "often/always" co-ordinate treatment plan with patients' family members, while only $57,6 \%$ of relatives thinks that they do. Some of this difference may reflect the state of stress of the patients' family members when they receive bad news about the prognosis of their loved ones in CIC settings. Acting as a surrogate decision maker is known to be a very stressful situation which can affect recalling of the information given [11]. Effective communication between critical care providers and surrogates, who are often family members, is a critical part of informed decision making regarding goals of care, including whether or not to pursue cardiopulmonary resuscitation in the intensive care unit [18]; End-of-life decisions for patients with surrogates usually are made at family conferences with participation of ethicists if needed [22]. Development of similar practice in Georgia would be highly appreciated.

The answer- "do not know" was rarely recorded except in the question regarding respect towards patient's spiritual attitudes and religiousness: 17 patients' family members $(28,8 \%)$ gave this answer, whereas none of the physicians did so. It was revealed that $40 \%$ of CIC physicians think that they "somewhat" considered patients' religious believes and faith. However, the response "somewhat", perhaps means, that medical staff simply addressed these aspects with restraint and/or hesitation, keeping a sense of distance. This restraint and hesitation on non-medical matters is reflected in the doubts of patients' family members regarding the physicians' attitudes towards patients'/patients' family members' religious and spiritual beliefs. The analyses of questionnaires indicate that physicians and patients' family members have significantly different attitudes towards consideration of such aspects during patient care. This probably does not contribute to development of confidence among communicating sides and may be considered as one of the main causes of patients' family members dissatisfaction by communication with $\mathrm{CIC}$ physicians. It appears physicians have the appropriate attitudes, just their knowledge and skills need improvement [23, 24].

Three-quarters (76.9\%) of $\mathrm{CIC}$ physicians as well as $57,6 \%$ of patients' family members confirm that physicians struggle and cannot talk freely, when discussing patient death with family members (Q1.9/Q2.9). Despite this fact, $78,5 \%$ of $\mathrm{CIC}$ physicians perceive communication with patients' family members as positive.

It is revealed that CIC physicians talk about patient death more frequently with patients' family members, than with the patients $(p<0,001)$. On the one hand, this reflects the fact that frequently it is difficult or impossible to communicate with the patients due to their altered consciousness. On the other hand, this fact might be explained by deficiency of relevant communication skills in "breaking bad news" related with the gap in professional education-on all levels of specialization [12].

Implementation of the recognized strategy - "Palliative Care for everyone who needs it"-necessarily requires that all medical professionals, who may be involved in the management of end-of-life patients, including CIC physicians, must be competent in basic knowledge and skills of palliative care [25-28].

However, adopted standards for palliative care require $\mathrm{CIC}$ physicians to ensure quality symptom control, pain relief and achievement of maximal physical comfort on the one hand, and consistency with humanistic goals on the other which is particularly important for patients and patients' family members [19]. They find it difficult to switch abruptly from the hope to survive and cure to preparation for dying and care at the end-of-life. Such transformation of medical care represents one of the most challenging steps in CIC settings [18, 29-31].

In general, both patients and patients' family members remain dissatisfied with the decision to quit the curative 
measures and continue only with palliative care. This is related with disappointments of their hopes [23, 32-34]. Poor communication skills of CIC physicians complicate understanding and collaboration among the CIC setting staff, patients and patients' family members. The persistence of the tradition of withholding the "bad diagnosis", as well as "stigma" and "taboo" associated with terminal illnesses in Georgia, further aggravates the problem [12].

CIC physicians have to deal with last days and hours of life exclusively in CIC settings, where the death is extremely common. Therefore, studies implemented during the last decade showed the absolute necessity for the development and improvement of palliative care service in CIC setting. palliative care in CIC may be implemented via two main models: a) "consultative model", when palliative care is delivered by invited specialists (consultants), who communicate with the patient and their family, develop, negotiate and implement the care plan themselves or supervise the process and b) "integrative model", when the care of the patient is delivered immediately by the staff of CIC setting on everyday basis. The second model is considered to be more cost-effective and adequate than the first one. In addition, it does not interfere with continuity of palliative care in specialized departments [12, 34-36].

Several indicators of good medical care at the end of life are identified: adequate management of pain and other symptoms, avoiding unnecessary and inexpedient prolongation of treatment, achieving sense of control, relieving burden to others and strengthening relationships with the loved ones. Effective communication with patient's family and consideration of their needs and wishes is equally important [37-41].

Before 2004 there was no official recognition of palliative care in Georgia. The updated standards of palliative carehave been introduced since 2004 by the implementation of pilot educational programs leaded by foreign experts [42] and aiming to give basic knowledge to healthcare professionals, policymakers and medical students. Later these were followed by approval of amendments in four laws of Georgia ("Law on Health Care", Law on Medical Activities", "Law on Narcotic Drugs, Psychotropic Substances and Precursors" and "Law on Patients Right") by Georgian Parliament, issuing decrees regulating palliative care and including "Palliative care and Pain Medicine" as a "subspecialty" in the list of medical specialties by Ministry of Health of Georgia in 2007 and 2008 [12].

In the light of these achievements, development of special training and qualification courses in palliative care for CIC physicians emerged as the urgent goal. In 2014 we (N. Chikhladze, M. Velijanashvili, D. Kordzaia) prepared the online-based learning course which was accredited by the Continued Education Council (Department) at Faculty of Medicine, TSU. The rationale for using an online course was the desire to allow CIC physicians to develop their knowledge without leaving their work place, which is particularly very important for CIC setting staff. Apart from the basic skills in palliative care including the peculiarities of communication with chronic incurable patients and their families regarding end-of-life, how the death may occur, faith and religion, etc., this course provides specific knowledge about palliative care in emergencies and specifically during the last $48 \mathrm{~h}$ of life, involving purely medical care as well as family support and ethical-religious aspects.

Restoring of mandatory system of continued medical education and professional development in Georgia from 2017 (this system was canceled in 2004) should support the successful implementation of this course.

There are some limitations in this study. The study was cross-sectional involving a convenient sample of patients' family members and physicians working in CIC settings. Therefore, this may affect generalisability of the present findings. Small sample size should also be mentioned, however, it was the first study conducted in Georgia to evaluate issues related to communication between physicians and patient representatives. Our study generated important evidence providing the basis for development of special training and qualification course in palliative care for CIC physicians.

\section{Conclusions}

The survey conducted in four cities of Georgia revealed the mismatch between the views of CIC physicians and family members of the patients with chronic incurable diseases receiving care in CIC settings - on communication topics covering possible deterioration of a patient's condition, future treatment plan, how death may occur, respect to patients' spiritual attitudes and religiousness. Only one quarter $(23.7 \%)$ of patients family members were satisfied with the communication level. The reason for their dissatisfaction was sense of inadequate appreciation of their needs and requirements. In contrast, $78.5 \%$ of physicians considered their communication with patients' family members as positive.

This mismatch indicates that in order to provide the best care for chronic incurable patients and their family members in a holistic way the physicians of CIC settings must have both relevant clinical knowledge and skills as well as the ability to provide effective communication with patients and their families.

The notable discordance in responses to similar questions as well as overall assessment of communication by physicians and patients' family members reflects important potential targets for educational interventions including CIC physicians training through online modules. 


\section{Additional file}

Additional file 1: Distribution of responses from physicians and patients' family members to question 1.1 and 1.2. Figure S2. Distribution of responses from physicians and patients' family members to question 1.2 and 2.2. Figure S3. Distribution of responses from physicians to question 1.3. Figure S4. Distribution of responses from physicians and patients' family members to question 1.4 and 2.4. Figure S5. Distribution of responses from physicians and patients' family members to question 1.5 and 2.5. Figure S6. Distribution of responses from physicians and patients' family members to question 1.6 and 2.6. Figure S7. Distribution of responses from physicians and patients' family members to question 1.7 and 2.7. Figure S8. Distribution of responses from physicians and patients' family members to question 1.8 and 2.8. Figure S9. Distribution of responses from physicians and patients' family members to question 1.9 and 2.9. Figure S10. Distribution of responses from physicians and patients' family members to question 1.10 and 2.10. (ZIP $702 \mathrm{~KB}$ )

\section{Abbreviations}

CIC, critical and intensive care; C.N., Chikhladze Nana; C.N., Chkhartishvili Nikoloz; DGPMIM, Department of Gerontology and Palliative Medicine of Alexandre Natishvili Institute of Morphology; GNAPC, Georgian National association for Palliative Care; J.E., Janberidze Elene; J.M., Jintcharadze Memed; K.D., Kordzaia Dimitri; TSU, Iv. Javakhishvili Tbilisi State University; V.J., Verne Julia; V.M. Velijanashvili Mariam

\section{Acknowledgments}

The authors are grateful to Dr. Frank D. Ferris (Exec Director, Palliative Medicine, Research, Education at OhioHealth, Honorary Doctor of TSU) for his assistance in identification of research concept. This study was supported by Al. Natishvili Institute of Morphology, TSU.

\section{Availability of data and materials}

Data were obtained from questionnaires and from standardised discharge/death certificates provided by patients' family members. The data are available at Al. Natishvili Institute of Morphology of Iv. Javakhishvili Tbilisi State University, and can be provided upon request from N.C., E.J and D.K. however, discharge/death certificates are confidential.

\section{Authors' contribution}

1. C.N.(1) created the design of the study, collected the interviews, analyzed and interpreted the data, drafted the manuscript. 2. J.E. has participated in creating of the study design, analysis and interpretation of data. 3. V.M. has participated in creating the outline of scientific concept of the study (aims, scope), drafting and revision of manuscript. 4. C.N.(2) has implemented the statistical treatment and analysis of data, drawing up the tables depicting the data analysis and results. 5. J.M. has implemented substantial part of interview collection, participated in the analysis of data. 6. V.J. has contributed significant work to critical revision of manuscript and final approval of the version to be published, also participated in the outline of scientific design of the study. 7. K.D. created the design of the study, performed the analysis and interpretation of the data, drafting of manuscript, critical revision of manuscript and final approval of the version to be published, made the general supervision of the research group. All authors read and approved the final manuscript.

\section{Competing interest}

The authors declare that they have no competing interests.

\section{Consent for publication}

Not applicable.

\section{Ethics approval and consent to participate}

The study involved the human participants. The study design was approved by the ethical committee of the Ivane Javakhishvili Tbilisi State University (TSU) in accordance with internationally recognized bio-ethical standards. Written informed consent was obtained from all participants. They gave consent to publish statement as the confidentiality of both participants and responses was ensured. Each participant was assigned unique study ID and only de-identified data was collected.
The manuscript was prepared in accordance with international standards for observational studies [43], also the guidelines for "ethics and consent" of BMC Palliative Care.

\section{Author details}

${ }^{1}$ IV. Javakhishvili Tbilisi State University (TSU), Tbilisi, Georgia. ${ }^{2}$ Department of Gerontology and Palliative Care, of Al. Natishvili Institute of Morphology, TSU, Tbilisi, Georgia. ${ }^{3}$ Georgian National Association for Palliative Care, Tbilisi, Georgia. ${ }^{4}$ Infectious Diseases, AIDS and Clinical Immunology Research Center, Tbilisi, Georgia. ${ }^{5}$ Public Health England, Bristol, UK.

Received: 10 April 2016 Accepted: 8 July 2016

Published online: 22 July 2016

\section{References}

1. Bekelman JE, Halpern SD, Blankart CR, Bynum JP, Cohen J, Fowler R, et al. Comparison of site of death, health care utilization, and hospital expenditures for patients dying with cancer in 7 developed countries. Jama. 2016;315(3):272-83. doi:10.1001/jama.2015.18603.

2. Vincent $J$ L, Berre J, Creteur J. Withholding and withdrawing life prolonging treatment in the intensive care unit: a current European perspective. Chron Respir Dis. 2004;1(2):115-20.

3. Gomes B, Higginson IJ, Calanzani N, et al. PRISMA. Preferences for place of death if faced with advanced cancer: a population survey in England, Flanders, Germany, Italy, the Netherlands, Portugal and Spain. Ann Oncol. 2012;23(8):2006-15.

4. Field MJ, Cassel CK. Approaching death: improving care at the end of life. National Academies Press; 1997 Oct 16

5. De Roo ML, Leemans K, Claessen SJ, Cohen J, Pasman HR, Deliens L, et al. Quality indicators for palliative care: update of a systematic review. J Pain Symptom Manage. 2013;46(4):556-72. doi:10.1016/j.jpainsymman.2012.09.013.

6. Addington-Hall J, Altmann D, McCarthy M. Variations by age in symptoms and dependency levels experienced by people in the last year of life, as reported by surviving family, friends and officials. Age Ageing. 1998;27(2):129-36.

7. Grudzen CR, Stone SC, Morrison RS. The palliative care model for emergency department patients with advanced illness. J Palliat Med. 2011;14(8):945-50. doi:10.1089/jpm.2011.0011.

8. Palda VA, Bowman KW, Mclean RF, Chapman MG. "Futile" care: do we provide it? Why? a semistructured, Canada-wide survey of intensive care unit doctors and nurses. J Crit Care. 2005;20(3):207-13. doi:10.1016/j.jcrc.2005.05.006.

9. Smith AK, Fisher J, Schonberg MA, Pallin DJ, Block SD, Forrow L, et al. Am I doing the right thing? provider perspectives on improving palliative care in the emergency department. Ann Emerg Med. 2009;54(1):86-93. doi:10.1016/ j.annemergmed.2008.08.022. e1.

10. Stone SC, Mohanty S, Grudzen CR, Shoenberger J, Asch S, Kubricek K, et al. Emergency medicine physicians' perspectives of providing palliative care in an emergency department. J Palliat Med. 2011;14(12):1333-8. doi:10.1089/ jpm.2011.0106.

11. Seymour JE. Negotiating natural death in intensive care. Soc Sci Med. 2000:51(8):1241-52. doi:10.1016/S0277-9536(00)00042-3.

12. Kordzaia D, Dalakishvili S, Gvamichava R, Rukhadze T, Abesadze I, Dzotsenidze P et al. Georgian National Program For Palliative Care, Action Plan for 2011 - 2015. 2011. (unpublished data).

13. Minister of Labour, Health, and Social Affairs of Georgia. Decree №136/N, Date of issuing: 18/04/2007 (with amendments in 07.02.2014). https:// matsne.gov.ge/en/document/view/70162. Accessed 21 June 2016.

14. Johnson DC, Kutner JS, Armstrong 2nd JD. Would you be surprised if this patient died?: preliminary exploration of first and second year residents' approach to care decisions in critically ill patients. BMC palliative care. 2003;2(1):1.

15. Rukhadze T., Kordzaia D., Velijanashvili M., Chikhladze N. Report of Survey funded by "Open Society_Georgia Foundation"(unpublished data). 2010

16. Luce JM. End-of-life decision making in the intensive care unit. Am J Respir Crit Care Med. 2010;182(1):6-11. doi:10.1164/rccm.201001-0071Cl.

17. Morgan J. End-of-life care in UK critical care units-a literature review. Nurs Crit Care. 2008;13(3):152-61. doi:10.1111/j.1478-5153.2008.00274.x

18. Truog RD, Campbell ML, Curtis JR, Haas CE, Luce JM, Rubenfeld GD, et al. Recommendations for end-of-life care in the intensive care unit: a consensus statement by the American college [corrected] of critical care medicine. Crit Care Med. 2008;36(3):953-63. doi:10.1097/CCM.0B013E3181659096.

19. Truog RD, Cist AF, Brackett SE, Burns JP, Curley MA, Danis M, et al. Recommendations for end-of-life care in the intensive care unit: the 
ethics committee of the society of critical care medicine. Crit Care Med. 2001;29(12):2332-48.

20. Agresti A. An introduction to categorical data analysis. 2nd ed. Wiley series in probability and mathematical statistics. Hoboken: Wiley-Interscience; 2007.

21. Government of Georgia, On Approval of the 2014-2020 State Concept of Healthcare System of Georgia for 'Universal Health Care and Quality Control for the Protection of Patients' Rights',. Registration code 470020000.10.003. $018343(26 / 12 / 2014)$.

22. Lynn J. Improving care for the end of life: A sourcebook for health care managers and clinicians. Oxford University Press; 2008.

23. Mazor KM, Beard RL, Alexander GL, Arora NK, Firneno C, Gaglio B, et al. Patients' and family members' views on patient-centered communication during cancer care. Psychooncology. 2013;22(11):2487-95. doi:10.1002/pon.3317.

24. Deledda G, Moretti F, Rimondini M, Zimmermann C. How patients want their doctor to communicate. A literature review on primary care patients' perspective. Patient Educ Couns. 2013;90(3):297-306. doi:10.1016/j.pec.2012.05.005.

25. Gomez-Batiste X, Caja C, Espinosa J, Bullich I, Martinez-Munoz M, Porta-Sales J, et al. The Catalonia world health organization demonstration project for palliative care implementation: quantitative and qualitative results at 20 years. J Pain Symptom Manage. 2012;43(4):783-94. doi:10.1016/j. jpainsymman.2011.05.006.

26. Gomez-Batiste X, Stjernsward J, Espinosa J, Martinez-Munoz M, Trelis J, Constante C. How to design and implement palliative care public health programmes: foundation measures. An operational paper by the WHO collaborating centre for public health palliative care programmes at the Catalan institute of oncology. BMJ Support Palliat Care. 2013;3(1):18-25. doi:10.1136/bmjspcare-2012-000215.

27. Stjernsward J.: Public health WHO perspective. In: Cohen J, Deliens L.: A public health perspective on end of life care. Oxford University Press; 2012 Jan 19., pp. 195-207

28. World Health Organization. Strengthening of palliative care as a component of integrated treatment throughout the life course. J Pain Palliat Care Pharmacother. 2014;28(2):130-4.

29. Eidelman LA, Jakobson DJ, Pizov R, Geber D, Leibovitz L, Sprung CL. Foregoing life-sustaining treatment in an Israeli ICU. Intensive Care Med. 1998;24(2):162-6.

30. A controlled trial to improve care for seriously ill hospitalized patients. The study to understand prognoses and preferences for outcomes and risks of treatments (SUPPORT). The SUPPORT Principal Investigators. Jama. 1995;274 (20):1591-8.

31. McLean RF, Tarshis J, Mazer CD, Szalai JP. Death in two Canadian intensive care units: institutional difference and changes over time. Critical Care Medicine. 2000;28(1):100-3.

32. Danis M. Improving end-of-life care in the intensive care unit: What's to be learned from outcomes research? New Horiz. 1998;6:110-8.

33. Curley MAQ, Meyer EC. The impact of the critical care experience on the family. In: critical care nursing of infants and children. Philadelphia: WB Saunders; 1999.

34. Furukawa MM. Meeting the needs of the dying patient's family. Crit Care Nurse. 1996;16(1):51-7.

35. Nelson JE, Cortez TB, Curtis JR, Lustbader DR, Mosenthal AC, Mulkerin C, et al. Integrating palliative care in the ICU: the nurse in a leading role. J Hosp Palliat Nurs : JHPN : off j Hosp Palliat Nurs Assoc. 2011;13(2):89-94. doi:10.1097/NJH. 0b013e318203d9ff.

36. Nelson JE, Bassett R, Boss RD, Brasel KJ, Campbell ML, Cortez TB, et al. Models for structuring a clinical initiative to enhance palliative care in the intensive care unit: a report from the IPAL-ICU Project (Improving Palliative Care in the ICU). Crit Care Med. 2010;38(9):1765-72. doi:10.1097/CCM. 0b013e3181e8ad23.

37. Singer PA, Martin DK, Kelner M. Quality end-of-life care: patients' perspectives. Jama. 1999;281(2):163-8.

38. Munhoz BA, Paiva HS, Abdalla BMZ, Zaremba G, Rodrigues AMP, Carretti MR, et al. From one side to the other: what is essential? perception of oncology patients and their caregivers in the beginning of oncology treatment and in palliative care. Einstein (São Paulo). 2014;12:485-91

39. Siaarti Italian Society of Anaesthesia Analgesia Resuscitation Intensive Care Bioethical Board. End-of-life care and the intensivist: SIAARTI recommendations on the management of the dying patient. Minerva Anestesiol. 2006;72(12):927-63.
40. Clarke EB, Curtis JR, Luce JM, Levy M, Danis M, Nelson J, et al. Quality indicators for end-of-life care in the intensive care unit. Crit Care Med. 2003;31(9):2255-62. doi:10.1097/01.CCM.0000084849.96385.85.

41. Cook D, Rocker G, Heyland D. Dying in the ICU: strategies that may improve end-of-life care. Canadian journal of anaesthesia = Journal canadien d'anesthesie. 2004;51 (3):266-72. doi:10.1007/BF03019109.

42. Stjernswärd J. National palliative care program: Georgia; 2006. http://www. parliament.ge/files/619_8111_336972_Paliativi-Eng.pdf.

43. PLOS Medicine Editors. Observational studies: getting clear about transparency. PLoS Med. 2014;11(8):e1001711.

\section{Submit your next manuscript to BioMed Central and we will help you at every step:}

- We accept pre-submission inquiries

- Our selector tool helps you to find the most relevant journal

- We provide round the clock customer support

- Convenient online submission

- Thorough peer review

- Inclusion in PubMed and all major indexing services

- Maximum visibility for your research

Submit your manuscript at www.biomedcentral.com/submit
Biomed Central 